\title{
DISPONIBILIDAD PARA EL EMPLEO: LO QUE ACEPTARÍA Y LO QUE NO ACEPTARÍA
}

\author{
AVAILABILITY FOR EMPLOYMENT: \\ WHAT I WOULD AND WOULD NOT ACCEPT \\ Miguel Aurelio Alonso García* \\ Universidad Complutense de Madrid
}

\section{RESUMEN}

En el presente estudio se valida un instrumento de evaluación para utilizar en el contexto de orientación laboral y se determinan los criterios de bondad del mismo. La muestra estaba formada por 313 individuos, el 54,6\% mujeres, y la edad media en los 27 años y medio. Poseen una formación muy heterogénea, de la misma forma que su situación laboral.

El instrumento presenta una serie de elementos que pretenden indagar sobre la disponibilidad de los individuos respecto a la búsqueda y consecución de empleo, y se pide al sujeto que evalué cada alternativa utilizando una escala tipo Likert de siete puntos. Los niveles de fiabilidad interna (alfa de Cronbach $=0,79$ ) y validez de constructo (análisis factorial) resultan bastante aceptables.

En función de los resultados del análisis factorial (seis factores que explican el 61,27\% de la información) se realiza un análisis de cluster que permite describir distintos grupos de sujetos y analizar las similitudes y diferencias entre ellos. Posteriormente, los resultados se validaron a través de análisis discriminante El análisis de conglomerados realizado permite distinguir entre cuatro grupos de individuos: aquellos que afirman poseer disponibilidad geográfica, pero no para puestos de trabajo que requieran esfuerzo físico; los que no tienen disponibilidad geográfica ni tampoco sobre horarios de trabajo poco frecuentes; las personas que afirman tener una disponibilidad total; $y$ las que aseguran no poseer disponibilidad en absoluto.

Palabras clave: Disponibilidad, búsqueda de empleo, habilidades en la búsqueda de empleo, orientación laboral, orientación profesional, orientación de carrera.

\section{ABSTRACT}

In the present study is validated an evaluation instrument to use in the occupational guidance context and are determined the kindness criteria of the same. The sample was formed by 313 individual,

* Departamento de Psicología Diferencial y del Trabajo. Facultad de Psicología. Universidad Complutense de Madrid. Campus de Somosaguas. 28223 Madrid. Dcho. 2226. Buzón 221. Tel. 913943198 / 918540061. m.alonso@psi.ucm.es. Líneas de investigación: orientación laboral, formación profesional, ocupacional, y continua, formación en prácticas. 
$54,6 \%$ women, and the mean age in 27 years and middle. Possess a very heterogeneous training, of the same form that their occupational situation.

The instrument presents a series of elements that intend to investigate on the availability of the individuals with respect to the search job. Is requested to the subject that I evaluated each alternative using a scale type Likert of seven points. The internal reliability levels (alpha of Cronbach $=0,79$ ) and validity of construct (factorial analysis) result quite acceptable.

In function of the results of the factorial analysis (six factors that explain $61,27 \%$ of the information) is accomplished an analysis of cluster that permits to describe different groups of subjects and to analyze the similarities and differences between them. Thereinafter, the results were validated through analysis discriminate you.

The accomplished conglomerates analysis permits to distinguish between four groups of individuals: those that they assert to possess geographical availability, but not for work place that require physical effort; those which do not have geographical availability neither either on hourly of work little frequent; the persons that assert to have a total availability; and those which assure not to possess availability absolutely.

Key words: Availability, job search, job search skills, occupational guidance, vocational guidance, career guidance.

\section{Introducción}

La mayor parte de los modelos relacionados con Orientación Laboral plantean la necesidad de evaluar en los individuos sus intereses, metas laborales, situación personal y familiar, cualificación, experiencia, etc. Además resulta necesario evaluar lo que un individuo estaría dispuesto a realizar para conseguir lo que quiere, sus actitudes ante la búsqueda de empleo, sus puntos fuertes y sus dificultades, y también sus miedos. Aunque todos estos aspectos sean positivos, aunque la persona tenga la formación y la experiencia suficiente para incorporarse a un puesto de trabajo, y haya necesidad de ese tipo de profesionales en el mercado laboral, es necesario que la persona quiera y pueda trabajar en ese puesto, y que acepte las condiciones del mismo.

Para que una persona trabaje en una determinada ocupación, y se mantenga en la misma, entre otros aspectos es necesario que quiera y pueda trabajar. La suma de ambos aspectos refleja lo que denominamos disponibilidad, variable especialmente relevante pues determina que se acepten o no determinados tipos de trabajos, pero no suficiente para trabajar ya que influyen otros aspectos como la situación del mercado de trabajo, características del propio individuo, la suerte, etc.

La Real Academia Española (1992) define disponibilidad como "cualidad o condición de disponible", y disponible: "dicese de la persona libre de impedimento para prestar servicios a otra u otras".

La Orden Ministerial de 11 de Marzo de 1.985 (B.O.E. de 14/3/85) establece los criterios estadísticos para la medición del Paro Registrado. Hace alusión a los demandantes de empleo no parados, y entre otros menciona los "demandantes sin disponibilidad inmediata para el trabajo o en situación incompatible con el mismo, como demandantes en situación de incapacidad laboral transitoria o de baja médica, demandantes que están cumpliendo el servicio militar o prestación social sustitutoria, demandantes inscritos para participar en un proceso de selección para un puesto de trabajo determinado, solicitantes de un empleo 
exclusivamente para el extranjero, demandantes de un empleo solo a domicilio, demandantes que en virtud de un expediente de regulación de empleo, están en situación de suspensión o reducción de jornada o modificación de las condiciones de trabajo, demandantes que son dados de alta como cotizantes a la Seguridad Social, etc. ”.

En Orden Ministerial incluye dentro del concepto de disponibilidad aspectos que tienen que ver con el querer y también con el poder. La disponibilidad para el empleo también es una variable que ha tenido en cuenta el Instituto Nacional de Empleo (www.inem.es) en la preselección de candidatos para un puesto de trabajo.

Otros organismos del área de la formación, como el Instituto Madrileño para la Formación (IMAF) toma en consideración, a efectos de baremación para la inclusión en los cursos de formación, a las personas que estén en situación de paro y con disponibilidad para incorporarse en el mercado laboral (www.comadrid.es).

Podrían distinguirse distintos tipos de disponibilidad: geográfica, temporal, salarial, en los desplazamientos, etc.; a continuación se detallan siete áreas que abarcaría:

- Disponibilidad geográfica: Referida al lugar más lejano donde la persona está dispuesta a trabajar. Habitualmente suele implicar un cambio de residencia, a no ser que no pueda o quiera trabajar en una ciudad distinta a la actual.

- Disponibilidad en los desplazamientos: Referida al lugar más lejano al que el individuo está dispuesto a desplazarse de forma diaria para acudir al trabajo. En ocasiones la disponibilidad estará limitada por la existencia de medios de transporte (si no se dispone de carnet de conducir o de coche) y en otras del tiempo que esté dispuesto a emplear en los desplazamientos diarios.

- Disponibilidad temporal: Alude al número de horas que el sujeto está dispuesto a trabajar al día y el horario y/o la jornada laboral que aceptaría. Trabajar los fines de semana, trabajar horas extras remuneradas o no, trabajar por las noches o los fines de semana son distintos ejemplos que pueden ser aceptados o rechazados.

- Disponibilidad salarial: Se refiere al sueldo anual o mensual mínimo por el que cada persona está dispuesta a trabajar.

- Disponibilidad sobre la estabilidad: Es decir, que tipo/s de contrato/s y con que duración/es aceptaría y cuales no estaría dispuesto a aceptar.

- Disponibilidad sobre la categoría laboral: Referido a aquellas categorías laborales que el individuo está dispuesto a aceptar y cuales no.

- Disponibilidad ocupacional: Se refiere a las ocupaciones o puestos de trabajo que tienen ciertas condiciones y que un individuo, por sus características físicas o psicológicas personales (posee alguna discapacidad o alguna enfermedad que le lleva a rechazarles) no podría aceptar o simplemente no querría.

La preocupación por el ajuste entre la oferta y la demanda por parte de las entidades relacionadas con el empleo es evidente. Son muchos los puestos de trabajo a los que se presentan varios candidatos y ninguno resulta finalmente seleccionado, o de otra forma, ocupaciones en que la demanda supera la oferta, pero las colocaciones están por debajo de dicha oferta. Una de las razones puede situarse en la falta de adecuación o de ajuste entre el individuo y el puesto, pero otra en que la persona rechace el puesto de trabajo. Un ejemplo de ello es la convocatoria de premiso como el del Consejo Económico y Social para el año 
2003, y que lleva por título: Desajustes entre la oferta y la demanda de trabajo en España: vacantes de trabajo no cubiertas y cambios sectoriales. Intermediación laboral y requerimientos formativos.

Las combinaciones de querer y poder ofrecen información sobre la disponibilidad de un individuo de cara a la búsqueda de empleo o a aceptar o rechazar un puesto de trabajo. No querer o no poder son aspectos modificables, el primero a través de información, asesoramiento, cambio de actitudes, etc.; el segundo a través de formación y la búsqueda de apoyos, etc.

Si se trata de estimar el grado de esfuerzo que desempeñará un individuo para alcanzar una meta (puesto de trabajo), en España se han aplicado los modelos de expectativa valencia en la búsqueda de empleo por autores como Aramburu-Zabala (1998), Fernández y Aramburu-Zabala (2000), y Piqueras y Rodríguez (1998).

\section{Objetivos}

Los principales objetivos que se pretenden con el estudio son los siguientes:

- Describir la disponibilidad de los individuos y aquellos puestos que aceptarían en función de sus características.

- Conocer cuales son las principales características que los individuos rechazan en un puesto de trabajo.

- Analizar como se agrupan los ítems del instrumento en factores

- Validar el instrumento, calculando la fiabilidad y validez del mismo

- Obtener, describir y validar distintos perfiles de individuos en función de su Disponibilidad.

- Detectar similitudes y diferencias entre los distintos patrones de Disponibilidad.

\section{Metodología}

La metodología utilizada se basa en el método transversal con diseños comparativos y correlacionales.

\section{Procedimiento}

La asignatura "Promoción de Empleo" se imparte como optativa para los alumnos de segundo curso de la Diplomatura de Relaciones Laborales en la Universidad Complutense de Madrid. Dicha materia tiene la mayor parte de sus contenidos centrados en la Orientación Laboral, ya que se entiende ésta como la estrategia básica de promoción de empleo, y una parte obligada son los instrumentos de evaluación.

En clase se realizó una práctica que pretendía verificar la validez de contenido de distintos protocolos de papel y lápiz que evaluaban distintas áreas de Orientación Laboral. Dichos protocolos recogían información sobre la situación de los individuos (personal, económica y respecto al empleo), cualificación (conocimientos, formación, y experien- 
cia), y planteamientos hacia la búsqueda de empleo. Además había seis escalas que pretendían evaluar los valores en la vida y en el trabajo, las actitudes (aquello que estaban o no estaban dispuestos a hacer para conseguir lo que deseaban), la disponibilidad (lo que podían o no podían aceptar), las dificultades y los miedos en la búsqueda y consecución de empleo.

En primer lugar se aplicaron los instrumentos a los alumnos para que se familiarizaran con ellos. Posteriormente, y con el objetivo de validar su contenido, se estableció un proceso de discusión que permitió modificar o eliminar aquellos ítems poco claros.

Una vez depurados los instrumentos se propuso a los alumnos realizar una aplicación masiva de los mismos, dicha actividad les permitiría adquirir destrezas con relación a la aplicación de pruebas y obtener datos sobre la fiabilidad y validez de cada escala.

La actividad era totalmente voluntaria, sólo aquellos alumnos que lo deseaban aplicaban las escalas a personas que estuvieran en situación de desempleo, buscando trabajo, o trabajando pero pensando en cambiar de empresa. Mediante la técnica que algunos denominan "bola de nieve" cada alumno, que deseo participar, aplicó los instrumentos a una o varias personas. Los datos fueron grabados por los alumnos, para ello se les facilitó la tabulación de los protocolos y una hoja de cálculo (Excel 97) en la que sólo tenían que cumplimentar los datos recogidos.

Una vez grabados los datos se procedió a unir los distintos ficheros, entregados en disquetes por los alumnos, y a la depuración de los mismos (también entregaban los protocolos cumplimentados). Se tomo la decisión de eliminar aquellos casos que no hubieran rellenado todas las escalas.

\section{Muestra}

La muestra era muy heterogénea, y en el protocolo de situación se les pidió información sobre su edad, estado civil, número de personas a su cargo, necesidad de ingresos en el tiempo, situación laboral, nivel de estudios, planteamientos respecto a la búsqueda de empleo, etc.

La muestra estaba formada por 313 individuos de los cuales el 45,4\% eran varones y el $54,6 \%$ mujeres. Su edad media era de 27 años y medio, la desviación típica 9,07, la mediana de 24 y la moda de 21. El 26,3\% de los individuos tenía entre 17 y 21 años, el 24,4\% entre 22 y 24 años, el $24,8 \%$ entre 25 y 29 años, y el $24,1 \%$ entre 30 y 57 años.

Para describir la muestra se siguen los epígrafes de situación, formación, empleo, y planteamientos.

\section{Situación}

Respecto al estado civil, 243 individuos son solteros (el 77,6\%) y 60 casados (el $19,2 \%$ ). El $86,6 \%$ vive con su familia y sólo un $17,8 \%$ tiene alguna persona a su cargo. Viven con tres o más personas el $83,1 \%$, solas 19 personas, y 34 en pareja.

Respecto a su situación económica, el 20,4\% afirma necesitar ingresos a medio plazo, el $36 \%$ en menos de un año, y de forma inmediata el $42,8 \%$. 


\section{Formación}

Respecto a su mayor nivel de estudios, 85 sujetos (el 27,2\% de la muestra) había cursado estudios superiores, el 38\% BUP, el 15,3\% Formación Profesional de segundo grado o ciclos de grado medio o superior, y el 19,5\% restante tiene unos estudios de FPI o inferiores.

129 individuos afirman estar estudiando en la actualidad, lo que supone el $41 \%$ sobre el total.

El 11,9\% de la muestra (37 individuos) afirman no poseer ningún conocimiento de inglés, un $26,2 \%$ conocimientos básicos, un $46 \%$ medios, y un $15,7 \%$ conocimientos altos. Sólo 45 individuos afirman poseer conocimientos medios o altos de francés, 8 de alemán y 4 de italiano.

Respecto a los conocimientos informáticos, 60 individuos afirman no manejar procesadores de textos, número que aumenta cuando se trata de hojas de cálculo (96 sujetos), u otros programas (209 individuos). El 18,5\% califica sus conocimientos de procesadores de texto como básicos, el 39,6\% como medios, y el 22,7\% como altos. Respecto a las hojas de cálculo, 148 sujetos valoran sus conocimientos como medios o altos.

Noventa personas no habían recibido nunca un curso de formación (el 28,9\%), uno o dos cursos los habían recibido 109 sujetos (el 35\%), y tres o más cursos 112 individuos (el $36 \%$ ). Respecto a las horas de formación recibidas, 35 individuos afirman que menos de 100 horas, 73 sujetos que entre 100 y 500 horas, y 113 sujetos más de 500 horas.

\section{Empleo}

Parece que 111 individuos están trabajando (el 35,9\%) y 198 están en desempleo (el $64,1 \%$ de la muestra). De los desempleados, 145 llevan en esa situación menos de un año y 53 más de un año. Las razones por las que están en esa situación son diversas: hasta ahora estudiaba, se dedicaba sólo a la casa y a la familia, le despidieron, se despidió, acabó su último contrato, etc. Se han agrupado en "no trabajaba anteriormente" (la situación de 83 sujetos que afirman estar en desempleo), y "despido o finalización del contrato" (el caso de 115 individuos).

Cuando se les pregunta si actualmente realizan algún tipo de actividad laboral, 156 individuos contestan afirmativamente, y 157 negativamente. Parece que la interpretación que hace cada persona de su situación actual respecto al empleo varía en función de la percepción que tengan de lo que es un empleo. 96 individuos dicen que están en desempleo y no cobran prestaciones, y 30 que las están cobrando actualmente. Afirman realizar algún trabajo esporádico, a pesar de estar en desempleo, 54 personas.

No han trabajado nunca 28 personas (el 8,9\% de la muestra), no han trabajado nunca pero han hecho prácticas 26 (el 8,3\%), sí han trabajado pero no cobraron por ello 8 (el $2,6 \%$ ), han trabajado pero no en puestos relacionados con sus estudios o los puestos que les gustaría desempeñar 156 (el 49,84\%), y 95 sujetos (el 30,4\%) han trabajado anteriormente en puestos de ésta índole.

De estos 95 individuos, el 26,7\% han trabajado en áreas relacionadas con sus estudios, o puestos en los que desearían trabajar durante menos de seis meses, el 21,7\% entre 6 meses y un año, y el 51,56\% durante más de un año. 
Entre aquellos que han trabajado anteriormente, 67 sujetos han tenido contratos indefinidos (el 21,5\%), 169 contratos temporales (el 54,2\%), 6 personas han trabajado siempre como autónomas (el 1,9\%), y 38 han trabajado siempre sin contrato (el 12,2\%), el resto afirman no haber trabajado nunca.

La mayor categoría profesional que han tenido ha sido la de licenciado (18 personas), diplomado (18), encargado (36), oficial de $1^{\mathrm{a}}(29)$, oficial de $2^{\mathrm{a}}(17)$, oficial de $3^{\mathrm{a}}(75)$, y aprendiz (78).

\section{Planteamientos}

Se les realizó una serie de preguntas de carácter dicotómico, los resultados de las mismas permiten describir con mayor exactitud los planteamientos de la muestra respecto a la búsqueda y consecución de empleo.

Doce individuos $(3,8 \%)$ afirman que descansarán durante una temporada antes de buscar trabajo; ochenta y nueve $(28,5 \%)$ que se formarán más, que ya tendrán tiempo de buscar trabajo; 53 (17\%) que buscarán cualquier tipo de trabajo; $165(53,7 \%)$ que buscarán sólo trabajos relacionados con sus estudios o puestos en los que quieren trabajar, y si no lo consiguen buscarán otro tipo de trabajos; y 62 (19,9\%) buscarán sólo trabajos relacionados con sus estudios o puestos en los que quieren trabajar.

De momento no han buscado trabajo 32 sujetos (el 10,3\%), lo han hecho en las oficinas de empleo 121 (el 38,9\%), a través de amigos y conocidos 201 (el 64,2\%), mediante anuncios en prensa 158 (el 50,6\%), en ofertas de la administración pública 47 (el 15\%), presentándose en empresas o llamándolas por teléfono 77 (el 24,7\%), inscribiéndose en bolsas de trabajo 58 (el 18,5\%), en empresas de trabajo temporal y agencias de colocación 125 $(40,1 \%)$, y en Internet 91 sujetos $(29,1 \%)$.

El 35,3\% de la muestra afirma no estar buscando trabajo en la actualidad (109 individuos), el $45,3 \%$ dice dedicar a la búsqueda de empleo algunos días de la semana (140 sujetos), y el 19,4\% restante dedicar algunas horas todos los días (60 personas).

Cincuenta y un individuos creen tener pocas posibilidades de encontrar trabajo (16,3\%), ciento treinta y siete regulares $(43,9 \%)$, y ciento veinticuatro muchas $(39,7 \%)$.

Esperan tardar menos de tres meses en conseguir trabajo 145 sujetos (el 46,8\%), de tres a seis meses 76 individuos (el 24,5\%), y más de seis meses 89 sujetos (el 28,7\%).

\section{Instrumento}

El instrumento aplicado a los sujetos estaba formado por veintiún ítems. Se pedía a los sujetos que señalaran las en que medida podrían aceptar una serie de condiciones laborales poco ( 1 o 2), regular (3), o mucho (4 o 5). Posteriormente se le solicitaba que ordenaran las diez condiciones que menos podrían aceptar.

Además se les pedía que indicaran el salario neto mínimo mensual por debajo del cual no trabajarían.

El instrumento no sólo tiene una finalidad cuantitativa, aspecto en el cuál se basa este artículo, sino también cualitativa en el contexto de intervención en Orientación Laboral. 


\section{Análisis de datos}

Para conseguir los distintos objetivos señalados anteriormente se han realizado los siguientes análisis de datos con el paquete estadístico SPSS 10.0:

- Para describir los ítems, los estadísticos de tendencia central y dispersión

- Para ordenar los ítems de disponibilidad se utiliza el un método de cálculo Promethee

- Para calcular la fiabilidad de la escala y las subescalas, el alfa de Cronbach.

- Para decidir que ítems de la escala se mantenían y cuáles se eliminaban se utilizan el alfa de la escala si se elimina el elemento, la correlación múltiple al cuadrado de cada elemento, y la correlación de cada ítem con el total.

- Para verificar la validez de constructo y analizar las distintas agrupaciones de ítems se utilizó el análisis factorial con ejes principales y rotación equamáx.

- Para la obtención de los perfiles de individuos se utilizaron, además del análisis factorial, el análisis de conglomerados. Y para la validación de dichos perfiles el análisis discriminante.

- Para detectar diferencias estadísticamente significativas entre los perfiles en función de distintas variables, el estadístico ji cuadrado $\left(\chi^{2}\right)$.

\section{Resultados}

\section{Descripción de los ítems y ordenación jerárquica de los mismos}

El ítem "que tenga riesgos para su seguridad o su salud" tiene una mediana y una moda de uno, y su media inferior a 1,5. Se decidió excluirle de los análisis de datos porque introducía un sesgo en los resultados, ya que muy pocos sujetos afirmaban poseer disponibilidad para puestos en los que pusieran en peligro su persona.

La escala se quedó con 20 elementos que obtuvieron un alfa de Cronbach de 0,79.

En el otro extremo, es decir, aquellos ítems con medias más altas y que los sujetos señalaron para expresar su máxima disponibilidad se corresponden con condiciones aparentemente atractivas ("con horario de mañana", "al que tardara en llegar entre 15 y 30 minutos"...).

En la figura 1 aparecen representadas las diez condiciones que los sujetos de la muestra menos podrían aceptar, en función del orden que otorgaron a los mismos.

Para ordenar las respuestas otorgadas por los sujetos se utilizó un método de cálculo denominado Promethee (Barba-Romero, 1984, 1987, 1990; Brans y Vincke, 1985). Este método se basa en las "relaciones de superación" que permiten establecer un pre-orden parcial en el conjunto de alternativas. Entre cada dos alternativas A y B se pueden dar tres posibilidades: A superior que B; B superior que A; y A y B son incomparables. Los cálculos se realizaron con el programa "Altor", creado por Pescador (1989) en lenguaje FORTRAN 77, y desarrollado posteriormente por Barrios y Rubio (1992).

El método Promethee utiliza el concepto de pseudocriterio según el cual una alternativa es mejor que otra, según un cierto criterio, si y sólo si tiene mejor puntuación en dicho criterio. Con ello se trata de reflejar que diferencias pequeñas entre dos alternativas pueden no 


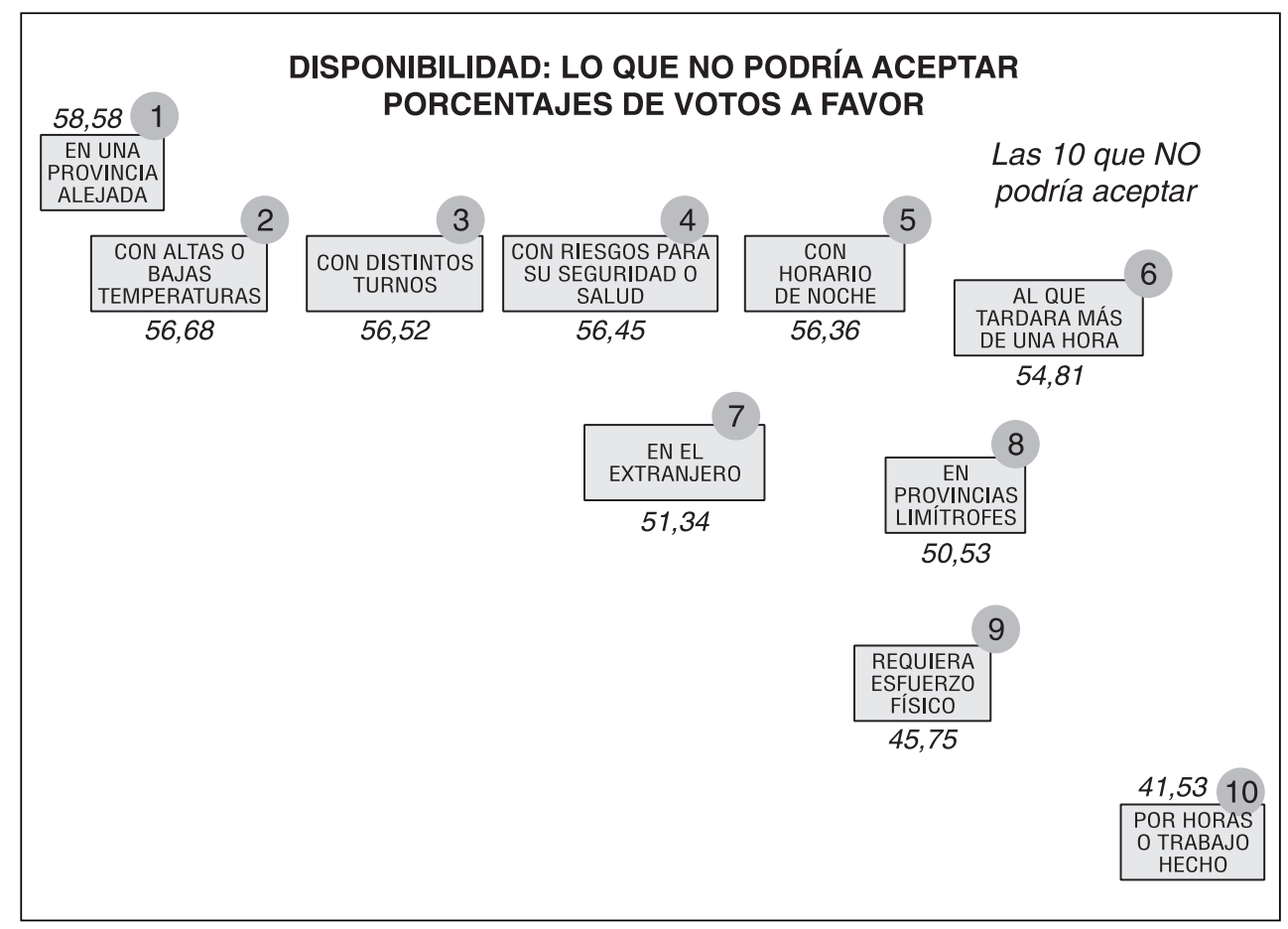

FIGURA 1.

Las 10 condiciones que los sujetos no podrían aceptar en un empleo.

ser significativas, y que a partir de un cierto valor de la diferencia la alternativa mejor lo es de forma absoluta y el incremento de tal diferencia no aumenta su grado.

Las condiciones sobre las que los individuos manifiestan tener menos disponibilidad, o sencillamente las que menos podrían aceptar en un puesto son las siguientes: situado en una provincia alejada, con altas o bajas temperaturas, con distintos turnos, con riesgos para la seguridad o salud, con horario de noche, al que tardara en llegar más de una hora, o que esté en el extranjero.

Las condiciones más deseables son tardar entre 15 y 30 minutos, horario de mañana, y que requiera utilizar la vista o el oído.

\section{Agrupaciones de los ítems y fiabilidad}

El análisis factorial (tabla 1) se realizó con los 313 sujetos y 20 ítems. Se obtuvieron seis factores que explicaban el $61,27 \%$ de la información. La medida de adecuación muestral de Kaiser-Meyer-Olkin ofrece un valor de 0,742 y la prueba de esfericidad de Bartlett resulta significativa $\left(\chi^{2}=1728,68 ;\right.$ g.l. $\left.=190 ; \mathrm{P}=0,0001\right)$, ambos valores indican que tiene sentido realizar el análisis factorial. 
TABLA 1: Análisis factorial (ejes principales, Normalización Equamax con Kaiser).

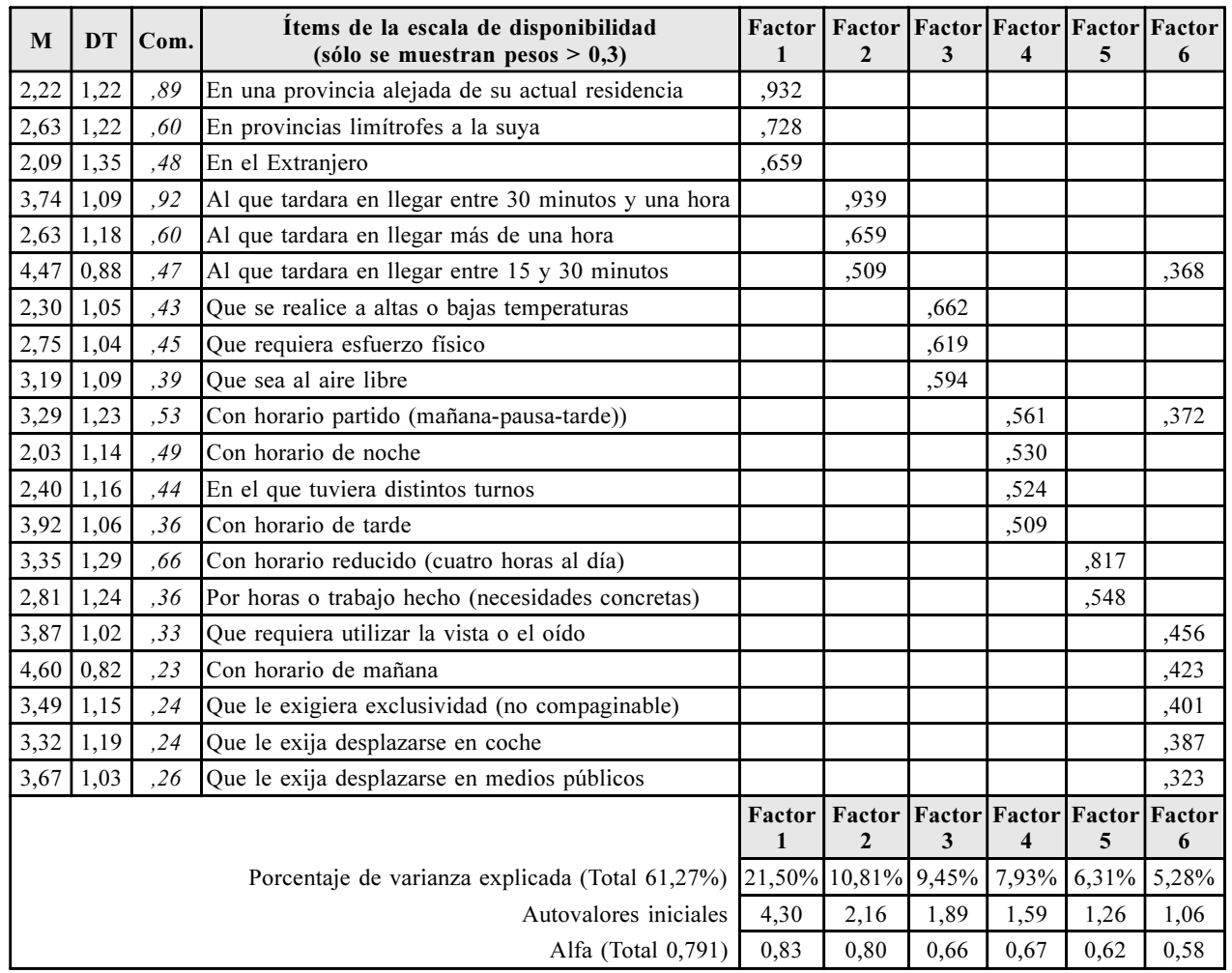

Factor 1: Disponibilidad Geográfica.

Factor 2: Disponibilidad en los desplazamientos.

Factor 3: Disponibilidad para realizar esfuerzos físicos.
Factor 4: Disponibilidad sobre horarios de trabajo raros. Factor 5: Disponibilidad sobre jornadas cortas.

Factor 6: Disponibilidad sobre condiciones de trabajo atractivas.

La fiabilidad total de la escala, calculada a través del test alfa de Cronbach, es de 0,79.

En el análisis factorial, con los ítems que saturaban en varios factores, se ha adoptado el criterio de incluirlos en aquel que lo hacían con mayor peso o en aquel que más incrementaba el alfa del factor.

El primer factor explica el $21,5 \%$ de la información y puede denominarse "Disponibilidad Geográfica”, y recoge en que medida los individuos podrían aceptar un trabajo en una provincia alejada de su actual residencia, en provincias limítrofes o en el extranjero La fiabilidad de estos tres elementos es de 0,83 (alfa de Cronbach).

El segundo factor explica el $10,81 \%$ de la varianza, sus ítems se refieren al tiempo que podrían aceptar tardar en llegar al trabajo, por ello se ha denominado "Disponibilidad en los desplazamientos". El alfa de los tres elementos que forman este factor (tardar en llegar entre 15 y 30 minutos, entre 30 minutos y una hora, y más de una hora) alcanza una fiabilidad de 0,80 . 
"Disponibilidad para realizar esfuerzos fisicos" es el tercer factor. Refleja la medida en que los sujetos aceptarían un puesto de trabajo al aire libre, con altas y/o bajas temperaturas, o que requiera esfuerzo físico. Explica el 9,45\% de la información y el alfa de sus ítems es de 0,66 .

El cuarto factor se refiere a la "Disponibilidad sobre horarios de trabajo raros" y reúne las modalidades de horario partido, nocturno, a turnos y horario de tarde. La fiabilidad de éstos cuatro elementos es 0,67 y el factor explica el 7,93\% de la varianza total.

El horario reducido y el trabajo por horas se agrupan en el quinto factor, que se ha denominado "Disponibilidad sobre jornadas cortas". Explica el 6,31\% de la información y sus ítems tienen un alfa de 0,62.

Es sexto y último factor agrupa los ítems de la escala que parece referirse a aspectos más atractivos:

- Un trabajo que requiera utilizar la vista o el oído (incluido para detectar problemas de disponibilidad por las características sensoriales, los sujetos parecen asociarlo a trabajos atractivos).

- Horario de mañana (en lugar de saturar en el factor cuatro, junto con los tipos de horarios, satura en el seis por la preferencia de los individuos hacia él).

- Exclusividad (asociado a jornada completa y por tanto a estabilidad), y

- Que exija desplazarse en coche o en medios de transportes públicos.

- Tardar en llegar al trabajo entre 15 y 30 minutos o tener un horario partido también parecen resultar atractivos, saturan en éste factor, pero con pesos más pequeños que en otros.

La fiabilidad de los cinco ítem del factor seis es de 0,58 y el factor "Condiciones de trabajo atractivas" explica el 5,28\% de la varianza.

Un nuevo análisis factorial, realizado eliminando los cinco ítems que saturan en el factor seis y el ítem "tardar menos de 15 minutos en llegar al trabajo", ofrece cinco factores, con la misma distribución de los actuales, y una varianza explicada del 68,34\%.

\section{Validez de constructo}

Para calcular la validez de constructo del instrumento se realizó un análisis factorial con todos los sujetos, otro con los casos pares y otro con los impares (en éste último se utilizó el método de componentes principales, ya que con ejes principales un ítem tenía una comunalidad superior a uno. Los resultados muestran el mismo número de factores en cada análisis, y estructuras similares en los tres análisis, tal y como puede observarse en la tabla 2. En mayúscula se señala aquel factor en el que cada ítem tiene un mayor peso, y en minúscula otros factores donde satura, cuando lo hace (sólo se señalan los pesos superiores a 0,3$)$.

Las estructuras factoriales entre el análisis realizado con todos los casos y el de los casos pares son muy similares, agrupándose los distintos ítems en los mismos factores, excepto el coche como medio obligado de desplazamiento que se une con los ítems de tiempo en llegar al trabajo. Los resultados obtenidos tras analizar los casos impares muestran diferencias más acusadas, pero las similitudes siguen predominando. 
TABLA 2: Comparación de los resultados de los análisis factoriales.

\begin{tabular}{|c|c|c|c|}
\hline ÍTEMS (sólo se muestran los pesos superiores a 0,3 ) & TOTAL & PARES & IMPARES \\
\hline En el Extranjero & F1 & F1 & F1 \\
\hline En una provincia alejada de su actual residencia & F1 & F1 & F1 \\
\hline En provincias limítrofes a la suya & $\mathrm{F} 1$ & F1 & F1 \\
\hline $\mathrm{Al}$ que tardara en llegar entre 15 y 30 minutos & $\mathrm{F} 2 / \mathrm{f6}$ & $\mathrm{F} 2 / \mathrm{f} 6$ & F3 \\
\hline Al que tardara en llegar entre 30 minutos y una hora & F2 & F2 & F3 \\
\hline $\mathrm{Al}$ que tardara en llegar más de una hora & F2 & $\mathrm{F} 2 / \mathrm{f} 4$ & $\mathrm{~F} 3 / \mathrm{f} 1$ \\
\hline Que requiera esfuerzo físico & F3 & F3 & F5 \\
\hline Que sea al aire libre & F3 & F3 & F5 \\
\hline Que se realice a altas o bajas temperaturas & F3 & F3 & F5 \\
\hline Con horario de noche & F4 & $\mathrm{F} 4 / \mathrm{fl}$ & $\mathrm{F} 2 / \mathrm{f5}$ \\
\hline En el que tuviera distintos turnos & F4 & $\mathrm{F} 4 / \mathrm{f3}$ & F2 \\
\hline Con horario de tarde & $\mathrm{F} 4$ & F4 & $\mathrm{F} 4 / \mathrm{f} 1 / \mathrm{f} 2$ \\
\hline Con horario partido (mañana - pausa - tarde) & F4/f6 & F4/f6 & $\mathrm{F} 4 / \mathrm{fl}$ \\
\hline Con horario reducido (cuatro horas al día) & F5 & F5 & F2/-f6 \\
\hline Por horas o por trabajo hecho (cuando haya necesidades concretas) & F5 & F5 & $\mathrm{F} 2 / \mathrm{f3}$ \\
\hline Con horario de mañana & F6 & F6 & F6 \\
\hline Que le exija desplazarse en coche & F6 & F6 & F6 \\
\hline Que le exija desplazarse en medios públicos & F6 & F2 & $\mathrm{F} 4 / \mathrm{f5}$ \\
\hline Que requiera utilizar la vista o el oído & F6 & F6/f3/f1 & F4 \\
\hline Que le exigiera exclusividad (no compaginable con otro) & F6 & $\mathrm{f} 6 / \mathrm{f} 4 / \mathrm{f} 2(<0,3)$ & $\mathrm{F} 4 / \mathrm{f} 6$ \\
\hline \multirow[t]{3}{*}{ Porcentaje de varianza explicada } & $61,27 \%$ & $62,44 \%$ & $62,85 \%$ \\
\hline & $\begin{array}{c}\text { Ejes } \\
\text { principales }\end{array}$ & $\begin{array}{c}\text { Ejes } \\
\text { principales }\end{array}$ & $\begin{array}{c}\text { Componentes } \\
\text { principales }\end{array}$ \\
\hline & $\begin{array}{c}\text { Equamáx con } \\
\text { Kaiser }\end{array}$ & $\begin{array}{c}\text { Equamáx con } \\
\text { Kaiser }\end{array}$ & $\begin{array}{c}\text { Varimáx con } \\
\text { Kaiser }\end{array}$ \\
\hline
\end{tabular}

\section{Perfiles de individuos}

\section{Proceso de creación}

Para la creación y descripción de distintos perfiles de individuos, en primer lugar, se transformaron las puntuaciones directas a puntuaciones T (media 50 y desviación típica 10). Se eligió este tipo de puntuaciones típicas derivadas pues facilitan la interpretación de los datos, permiten establecer comparaciones entre grupos de individuos, y comparar entre sí las puntuaciones obtenidas en distintas pruebas.

Puesto que los resultados del test alfa de Cronbach en cada factor son aceptables, se procedió a crear seis nuevas variables o índices, basadas en los resultados del análisis factorial. Entre los distintos métodos posibles se optó por multiplicar el peso de cada ítem por su puntuación directa, y sumar los resultados calculando una puntuación (índice) por cada uno de los factores. 


$$
F_{i_{1,6}}=\sum_{j=1}^{n} a * x_{i}
$$

$a$ : peso de la variable en el factor

$x_{i}: \quad$ puntuación directa

$j: \quad \operatorname{casos}$

$i$ : factores

Los índices recibieron el mismo nombre que los factores, ya que habían sido obtenidos a través de éstos. Una vez calculados se realizó un análisis de conglomerados de $\mathrm{K}$ medias para ver como se agrupaban los individuos. Estos cluster fueron validados posteriormente a través de la técnica de análisis discriminante.

La elección del número de cluster se realizó en función del número de iteraciones del análisis de conglomerados, la distancia mínima entre los centros iniciales, el número de sujetos de cada cluster, y los perfiles resultantes.

\section{Descripción de los patrones}

Se eligieron cuatro conglomerados porque se formaban a una distancia mínima de 57,054 y a partir de cuatro cluster los cambios en la distancia eran muy pequeños.

Las medias (en puntuaciones $\mathrm{T}$ ) de los seis índices en los cuatro conglomerados aparecen en la tabla 3, y la representación gráfica de la misma en la figura 2.

\section{TABLA 3: Patrones de Disponibilidad: Análisis de Conglomerados (Puntuaciones T: medias).}

\begin{tabular}{|l|c|c|c|c|}
\hline \multicolumn{1}{|c|}{ ÍNDICES } & $\begin{array}{c}\text { Cluster 1: Disp. } \\
\text { Geográfica pero } \\
\text { sin esfuerzo } \\
\text { físico }\end{array}$ & $\begin{array}{c}\text { Cluster 2: Sin } \\
\text { disp. geográfica } \\
\text { ni disp. sobre } \\
\text { horarios }\end{array}$ & $\begin{array}{c}\text { Cluster 3: } \\
\text { Disponiblidad } \\
\text { total }\end{array}$ & $\begin{array}{c}\text { Cluster 4: Sin } \\
\text { disponibilidad }\end{array}$ \\
\hline $\begin{array}{l}\text { Disponibilidad } \\
\text { geográfica }\end{array}$ & 60,84 & 43,38 & 53,81 & 42,94 \\
\hline $\begin{array}{l}\text { Disponibilidad en } \\
\text { desplazamientos }\end{array}$ & 53,68 & 50,30 & 55,59 & 36,74 \\
\hline $\begin{array}{l}\text { Disponibilidad } \\
\text { esfuerzo físico }\end{array}$ & 45,48 & 50,02 & 59,54 & 44,73 \\
\hline $\begin{array}{l}\text { Dispon. Horarios } \\
\text { de trabajo raros }\end{array}$ & 52,73 & 45,81 & 60,79 & 41,18 \\
\hline $\begin{array}{l}\text { Disponibilidad } \\
\text { jornadas cortas }\end{array}$ & 47,52 & 51,63 & 55,85 & 42,87 \\
\hline $\begin{array}{l}\text { Condiciones } \\
\text { atractivas }\end{array}$ & 48,11 & 50,98 & 57,77 & 40,94 \\
\hline
\end{tabular}

Se tomó como punto de corte el señalado por el grupo de investigación MOW (1987), que distingue entre puntuaciones bajas (menores de 46), medias (entre 46 y 54), y altas (mayores de 54). 


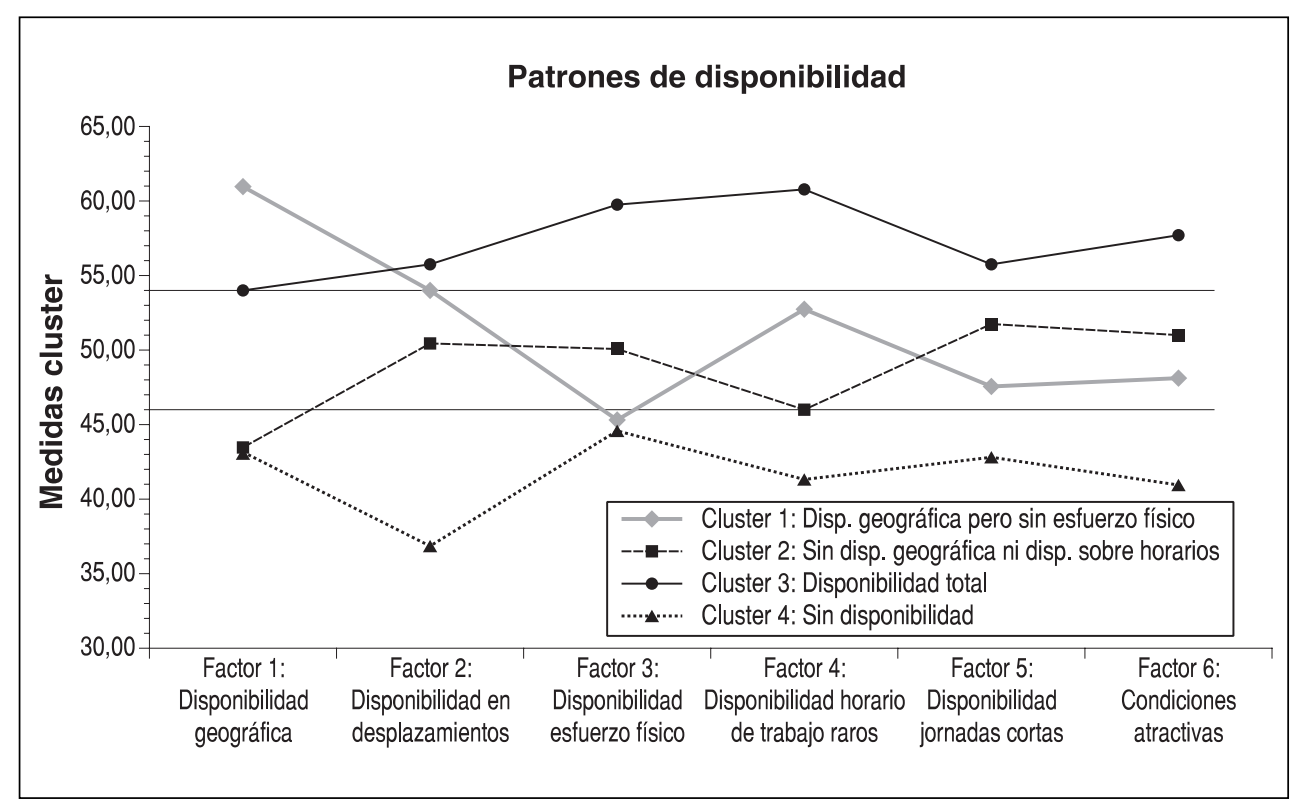

FIGURA 2.

Patrones de disponibilidad hacia el empleo.

En la figura 2 se pueden observar cuatro patrones o perfiles de individuos que también aparecen descritos a continuación:

- Cluster 1: Disponibilidad geográfica, pero no en puestos de trabajo que requieran esfuerzo físico

Son individuos que podrían aceptar puestos de trabajo en provincias limítrofes o alejadas de su actual residencia, o incluso en el extranjero, pero que afirman no poder o no querer aceptarlos si se realizan en condiciones de temperaturas extremas, al aire libre o si requiere esfuerzo físico. En éste conglomerado se agrupan 80 individuos.

- Cluster 2: Sin disponibilidad geográfica ni sobre horarios de trabajo poco frecuentes

Manifiestan no poder aceptar puestos de trabajo fuera de su provincia o en horarios distintos al de mañana. Está formado por 113 sujetos, y el cluster más numeroso.

- Cluster 3: Disponibilidad Total

Los 67 individuos que se agrupan en este cluster afirman tener Disponibilidad total: en los desplazamientos, condiciones ambientales, jornadas cortas y condiciones atractivas. Además tampoco parecen carecer de Disponibilidad geográfica.

\section{- Cluster 4: Sin Disponibilidad}

En este grupo se reúnen 53 individuos que dicen no tener Disponibilidad para nada, ni siquiera para aceptar condiciones atractivas. ¿Querrán trabajar? 


\section{Validación de los patrones}

Se realizó un Análisis Discriminante para validar los cuatro patrones obtenidos. Las tres funciones obtenidas son significativas y ayudan a describir los patrones (Tablas 4 y 5 ).

TABLA 4: Características de las funciones discriminantes.

\begin{tabular}{|l|c|c|c|c|c|c|}
\hline & Autovalor & $\begin{array}{c}\text { \% de } \\
\text { varianza }\end{array}$ & Chi-cuadrado & gl & Sig. & $\begin{array}{c}\text { Correlación } \\
\text { canónica }\end{array}$ \\
\hline Función 1 & 2,651 & $63,53 \%$ & 709,208 & 18 & 0,0001 & 0,852 \\
\hline Función 2 & 1,344 & $32,22 \%$ & 311,682 & 10 & 0,0001 & 0,757 \\
\hline Función 3 & 0,177 & $4,25 \%$ & 50,152 & 4 & 0,0001 & 0,388 \\
\hline
\end{tabular}

TABLA 5: Índices de Disponibilidad: Análisis Discriminante: Coeficientes estandarizados de las funciones discriminantes canónicas.

\begin{tabular}{|l|c|c|c|}
\hline \multicolumn{1}{|c|}{ Índices } & Función 1 & Función 2 & Función 3 \\
\hline Disponibilidad geográfica & 0,434 & $\mathbf{- 0 , 8 0 6}$ & $-0,029$ \\
\hline Disponibilidad en desplazamientos & $\mathbf{0 , 4 8 5}$ & 0,190 & $\mathbf{0 , 7 0 4}$ \\
\hline Disponibilidad de esfuerzo físico & 0,318 & $\mathbf{0 , 5 4 2}$ & $-0,392$ \\
\hline Disponibilidad sobre horarios de trabajo raros & $\mathbf{0 , 5 7 1}$ & $-0,049$ & $\mathbf{- 0 , 5 0 6}$ \\
\hline Disponibilidad jornadas cortas & 0,326 & $\mathbf{0 , 4 7 1}$ & 0,215 \\
\hline Condiciones atractivas & 0,233 & 0,354 & 0,096 \\
\hline
\end{tabular}

En la primera función, que explica la mayor parte de la información $(63,53 \%)$ los índices que más contribuyen (tomando como criterio que el coeficiente sea igual o superior a 0,45, tal y como proponen Tabachnick y Fidell, 1983) son disponibilidad sobre horarios raros y sobre desplazamientos. Parece que tener o no esos dos tipos de disponibilidad es lo que más influye a la hora de formar los cuatro cluster.

La segunda función explica el 32,22\% de la información, y en ella destacan con valores superiores a 0,45 los índices "disponibilidad de esfuerzo físico", "disponibilidad sobre jornadas cortas", y "Disponibilidad geográfica", ésta última con signo negativo. Parece que los individuos que estarían dispuestos a aceptar puestos que requieran esfuerzo físico o que supongan exponerse a temperaturas extremas, aunque fueran a media jornada o por trabajo hecho, no estarían dispuestos a cambiar de residencia para realizarlos.

La tercera función explica una pequeña parte de la varianza $(4,25 \%)$, y en ella parecen oponerse disponibilidad en los desplazamientos y disponibilidad sobre horarios de trabajo distintos al de mañana.

El análisis discriminante permite validar los resultados obtenidos con el análisis de conglomerados, ya que clasifica correctamente el 94,9\% de los sujetos (Tabla 6). 
TABLA 6: Resultados de la clasificación.

\begin{tabular}{|c|c|c|c|c|c|c|}
\hline & $\begin{array}{c}\text { CLUSTER } \\
\mathbf{1}\end{array}$ & $\begin{array}{c}\text { CLUSTER } \\
\mathbf{2}\end{array}$ & $\begin{array}{c}\text { CLUSTER } \\
\mathbf{3}\end{array}$ & $\begin{array}{c}\text { CLUSTER } \\
\mathbf{4}\end{array}$ & Total & $\begin{array}{c}\text { \% clasificaciones } \\
\text { correctas }\end{array}$ \\
\hline CLUSTER 1 & 78 & 2 & 0 & 0 & $\mathbf{8 0}$ & $97,50 \%$ \\
\hline CLUSTER 2 & 0 & 113 & 0 & 0 & $\mathbf{1 1 3}$ & $100,00 \%$ \\
\hline CLUSTER 3 & 3 & 7 & 57 & 0 & $\mathbf{6 7}$ & $85,10 \%$ \\
\hline CLUSTER 4 & 0 & 4 & 0 & 49 & $\mathbf{5 3}$ & $92,50 \%$ \\
\hline Total & $\mathbf{8 1}$ & $\mathbf{1 2 6}$ & $\mathbf{5 7}$ & $\mathbf{4 9}$ & $\mathbf{3 1 3}$ & $\mathbf{9 4 , 9 0 \%}$ \\
\hline
\end{tabular}

\section{Similitudes y diferencias entre los perfiles}

Para calcular las similitudes y diferencias entre los distintos patrones de disponibilidad se utilizó el estadístico $\chi^{2}$. A continuación se mencionan aquellas variables en las que existían diferencias estadísticamente significativas entre los cluster (la relación de variables descriptivas con sus alternativas de respuesta aparece en Anexo I).

En función de la variable edad, parece que, proporcionalmente, los individuos que tienen entre 22 y 24 años se agrupan más en el cluster "Disponibilidad geográfica, pero no en puestos de trabajo que requieran esfuerzo fisico"; los menores de 21 años lo hacen en el conglomerado denominado "Sin disponibilidad geográfica ni sobre horarios de trabajo poco frecuentes"; entre 25 a 29 años los que poseen "Disponibilidad total"; y más de 30 años las personas del grupo "Sin Disponibilidad" (Tabla 7).

TABLA 7: Patrones de Disponibilidad y grupos de edad.

\begin{tabular}{|c|c|c|c|c|c|c|}
\hline & & $\begin{array}{c}\text { Disponibilidad } \\
\text { geográfica, no } \\
\text { para esfuerzo } \\
\text { físico } \\
\end{array}$ & $\begin{array}{c}\text { Sin disp. } \\
\text { Geográfica y } \\
\text { sin disp. De } \\
\text { horarios raros } \\
\end{array}$ & $\begin{array}{c}\text { Disponibilidad } \\
\text { total }\end{array}$ & $\begin{array}{c}\text { Sin } \\
\text { Disponibilidad }\end{array}$ & Total \\
\hline \multirow{5}{*}{ EDAD } & De 17 a 21 & $\begin{array}{c}19 \\
23,2 \%\end{array}$ & $\begin{array}{c}41 \\
50,0 \%\end{array}$ & $\begin{array}{c}14 \\
17,1 \%\end{array}$ & $\begin{array}{c}8 \\
9,8 \%\end{array}$ & $\begin{array}{c}82 \\
100,0 \%\end{array}$ \\
\hline & De 22 a 24 & $\begin{array}{c}25 \\
32,9 \% \\
\end{array}$ & $\begin{array}{c}27 \\
35,5 \% \\
\end{array}$ & $\begin{array}{c}15 \\
19,7 \% \\
\end{array}$ & $\begin{array}{c}9 \\
11,8 \% \\
\end{array}$ & $\begin{array}{c}76 \\
100,0 \% \\
\end{array}$ \\
\hline & De 25 a 29 & $\begin{array}{c}20 \\
25,6 \%\end{array}$ & $\begin{array}{c}21 \\
26,9 \%\end{array}$ & $\begin{array}{c}26 \\
33,3 \%\end{array}$ & $\begin{array}{c}11 \\
14,1 \%\end{array}$ & $\begin{array}{c}78 \\
100,0 \%\end{array}$ \\
\hline & De 30 a 57 & $\begin{array}{c}16 \\
21,1 \% \\
\end{array}$ & $\begin{array}{c}24 \\
31,6 \% \\
\end{array}$ & $\begin{array}{c}11 \\
14,5 \%\end{array}$ & $\begin{array}{c}25 \\
32,9 \%\end{array}$ & $\begin{array}{c}76 \\
100,0 \%\end{array}$ \\
\hline & Total & $\begin{array}{c}80 \\
25,6 \%\end{array}$ & $\begin{array}{c}113 \\
36,2 \%\end{array}$ & $\begin{array}{c}66 \\
21,2 \%\end{array}$ & $\begin{array}{c}53 \\
17,0 \%\end{array}$ & $\begin{array}{c}312 \\
100,0 \%\end{array}$ \\
\hline
\end{tabular}

$$
\chi^{2}=32,2 ; \text { g.l. }=9 ; \quad \mathrm{P}=0,0001
$$

Si se tiene en cuenta el estado civil $\left(\chi^{2}=31,1 ;\right.$ g.l. $\left.=3 ; \mathrm{P}=0,0001\right)$ y el número de personas que tienen a su cargo $\left(\chi^{2}=18,595 ;\right.$ g.l. $\left.=3 ; \mathrm{P}=0,0001\right)$, los casados con uno o 
más individuos a su cargo, proporcionalmente, predominan en el cluster "sin disponibilidad", y los solteros sin personas a su cargo en el de "Disponibilidad total" y en el de "Sin disponibilidad geográfica ni sobre horarios de trabajo poco frecuentes".

$\mathrm{Si}$ se atiende a la distribución de los individuos en función de la variable "vive con" $\left(\chi^{2}=13,985 ;\right.$ g.l. $\left.=3 ; \mathrm{P}=0,003\right)$, viven con su familia aquellos del cluster "Sin disponibilidad geográfica ni sobre horarios de trabajo poco frecuentes"; y viven por su cuenta, proporcionalmente, aquellos que afirman tener una disponibilidad total o carecer de ella.

Proporcionalmente, parece que no están estudiando en la actualidad los individuos del cluster denominado "sin disponibilidad" $\left(\chi^{2}=10,096 ;\right.$ g.l. $\left.=3 ; \mathrm{P}=0,018\right)$.

Si se analiza el mayor nivel de estudios de los individuos, proporcionalmente, el grupo que posee formación profesional de primer grado o inferior destaca en el cluster "sin disponibilidad", los que poseen formación profesional de segundo grado en el cluster "Sin disponibilidad geográfica ni sobre horarios de trabajo poco frecuentes", los que poseen BUP en el conglomerado "Disponibilidad Total" y los que tienen estudios superiores en el cluster de "Disponibilidad geográfica, pero no en puestos de trabajo que requieran esfuerzo físico" (Tabla 8).

TABLA 8: Patrones de disponibilidad y mayor nivel de estudios.

\begin{tabular}{|c|c|c|c|c|c|c|}
\hline & & $\begin{array}{l}\text { Disponibilidad } \\
\text { geográfica, no } \\
\text { para esfuerzo } \\
\text { físico }\end{array}$ & $\begin{array}{c}\text { Sin disp. } \\
\text { geográfica y } \\
\text { sin disp. de } \\
\text { horarios raros }\end{array}$ & $\begin{array}{c}\text { Disponibilidad } \\
\text { total }\end{array}$ & $\underset{\text { Sin }}{\text { disponibilidad }}$ & Total \\
\hline \multirow{5}{*}{$\begin{array}{l}\text { Mayor } \\
\text { nivel de } \\
\text { estudios }\end{array}$} & $\begin{array}{l}\text { Menor de } \\
\text { FPI }\end{array}$ & $\begin{array}{c}11 \\
18,0 \%\end{array}$ & $\begin{array}{c}21 \\
34,4 \%\end{array}$ & $\begin{array}{c}7 \\
11,5 \%\end{array}$ & $\begin{array}{c}22 \\
36,1 \%\end{array}$ & $\begin{array}{c}61 \\
100,0 \%\end{array}$ \\
\hline & $\begin{array}{l}\text { FPII o } \\
\text { ciclos }\end{array}$ & $\begin{array}{c}8 \\
16,7 \%\end{array}$ & $\begin{array}{c}24 \\
50,0 \%\end{array}$ & $\begin{array}{c}9 \\
18,8 \%\end{array}$ & $\begin{array}{c}7 \\
14,6 \%\end{array}$ & $\begin{array}{c}48 \\
100,0 \%\end{array}$ \\
\hline & BUP & $\begin{array}{c}28 \\
23,5 \%\end{array}$ & $\begin{array}{c}45 \\
37,8 \%\end{array}$ & $\begin{array}{c}33 \\
27,7 \%\end{array}$ & $\begin{array}{c}13 \\
10,9 \%\end{array}$ & $\begin{array}{c}119 \\
100,0 \%\end{array}$ \\
\hline & \begin{tabular}{|l} 
Estudios \\
superiores
\end{tabular} & $\begin{array}{c}33 \\
38,8 \%\end{array}$ & $\begin{array}{c}23 \\
27,1 \%\end{array}$ & $\begin{array}{c}18 \\
21,2 \%\end{array}$ & $\begin{array}{c}11 \\
12,9 \%\end{array}$ & $\begin{array}{c}85 \\
100,0 \%\end{array}$ \\
\hline & Total & $\begin{array}{c}80 \\
25,6 \%\end{array}$ & $\begin{array}{c}113 \\
36,1 \%\end{array}$ & $\begin{array}{c}67 \\
21,4 \%\end{array}$ & $\begin{array}{c}53 \\
16,9 \%\end{array}$ & $\begin{array}{c}313 \\
100,0 \%\end{array}$ \\
\hline
\end{tabular}

$$
\chi^{2}=35,393 ; \text { g.l. }=9 ; \quad P=0,0001
$$

Parecen estar recibiendo un curso de formación en la actualidad los individuos de los cluster "Disponibilidad geográfica, pero no en puestos de trabajo que requieran esfuerzo fisico" y "Disponibilidad Total", mientras que los sujetos del grupo "Sin disponibilidad geográfica ni sobre horarios de trabajo poco frecuentes" no se están formando $\left(\chi^{2}=12,803\right.$; g.l. $=3 ; \mathrm{P}=0,005)$.

Respecto a los cursos $\left(\chi^{2}=12,803\right.$; g.l. $\left.=3 ; \mathrm{P}=0,005\right)$ y horas de formación recibidas anteriormente $\left(\chi^{2}=15,628\right.$; g.l. $\left.=6 ; \mathrm{P}=0,016\right)$, parece que proporcionalmente no han recibido ningún curso los individuos del grupo "Sin Disponibilidad", dos o menos cur- 
sos y menos de 500 horas lectivas los del cluster "Sin disponibilidad geográfica ni sobre horarios de trabajo poco frecuentes", y han recibido más de un curso y más de 500 horas los que poseen "Disponibilidad geográfica, pero no en puestos de trabajo que requieran esfuerzo físico”.

Respecto al nivel de inglés, poseen conocimientos básicos o inferiores los sujetos de los cluster "Sin disponibilidad", y "Sin disponibilidad geográfica ni sobre horarios de trabajo poco frecuentes", y conocimientos medios o altos los del grupo "Disponibilidad geográfica, pero no en puestos de trabajo que requieran esfuerzo físico" y los del conglomerado "Disponibilidad Total" $\left(\chi^{2}=8,708 ;\right.$ g.l. $\left.=3 ; \mathrm{P}=0,033\right)$.

Parece que también existen diferencias estadísticamente significativas en el tiempo que llevan en desempleo los individuos de los distintos grupos (Tabla 9), destacan proporcionalmente entre los que no están en desempleo los sujetos del cluster "Disponibilidad Total", llevan menos de un año o no lo están los del conglomerado grupo "Disponibilidad geográfica, pero no en puestos de trabajo que requieran esfuerzo físico", y entre los que llevan más de un año en desempleo destacan los individuos del cluster "Sin Disponibilidad".

TABLA 9: Patrones de Disponibilidad y tiempo en desempleo.

\begin{tabular}{|c|c|c|c|c|c|c|}
\hline & & $\begin{array}{l}\text { Disponibilidad } \\
\text { geográfica, no } \\
\text { para esfuerzo } \\
\text { físico }\end{array}$ & $\begin{array}{c}\text { Sin disp. } \\
\text { Geográfica y } \\
\text { sin disp. de } \\
\text { horarios raros }\end{array}$ & $\begin{array}{c}\text { Disponibilidad } \\
\text { total }\end{array}$ & $\begin{array}{c}\text { Sin } \\
\text { disponibilidad }\end{array}$ & Total \\
\hline \multirow{4}{*}{$\begin{array}{l}\text { Tiempo en } \\
\text { desempleo }\end{array}$} & $\begin{array}{l}\text { No está en } \\
\text { desempleo }\end{array}$ & $\begin{array}{c}28 \\
25,2 \%\end{array}$ & $\begin{array}{c}37 \\
33,3 \%\end{array}$ & $\begin{array}{c}28 \\
25,2 \%\end{array}$ & $\begin{array}{c}18 \\
16,2 \%\end{array}$ & $\begin{array}{c}111 \\
100,0 \%\end{array}$ \\
\hline & $\begin{array}{l}\text { Menos de } \\
\text { un año }\end{array}$ & $\begin{array}{c}42 \\
29,0 \%\end{array}$ & $\begin{array}{c}57 \\
39,3 \%\end{array}$ & $\begin{array}{c}28 \\
19,3 \%\end{array}$ & $\begin{array}{c}18 \\
12,4 \%\end{array}$ & $\begin{array}{c}145 \\
100,0 \%\end{array}$ \\
\hline & $\begin{array}{l}\text { Más de un } \\
\text { año }\end{array}$ & $\begin{array}{c}9 \\
17,0 \%\end{array}$ & $\begin{array}{c}18 \\
34,0 \%\end{array}$ & $\begin{array}{c}10 \\
18,9 \%\end{array}$ & $\begin{array}{c}16 \\
30,2 \%\end{array}$ & $\begin{array}{c}53 \\
100,0 \%\end{array}$ \\
\hline & Total & $\begin{array}{c}79 \\
25,6 \%\end{array}$ & $\begin{array}{c}112 \\
36,2 \%\end{array}$ & $\begin{array}{c}66 \\
21,4 \%\end{array}$ & $\begin{array}{c}52 \\
16,8 \%\end{array}$ & $\begin{array}{c}309 \\
100,0 \%\end{array}$ \\
\hline
\end{tabular}

$$
\chi^{2}=11,441 ; \text { g.l. }=6 ; \quad \mathrm{P}=0,0076
$$

Respecto a las razones por las que están en desempleo, los que no trabajaban se agrupan, proporcionalmente, en el cluster "Disponibilidad geográfica, pero no en puestos de trabajo que requieran esfuerzo físico" y les despidieron o no les renovaron el contrato a los sujetos de los grupos "Sin disponibilidad geográfica ni sobre horarios de trabajo poco frecuentes" y "Sin Disponibilidad" (Tabla 10).

Respecto a la máxima categoría profesional, y de nuevo proporcionalmente, han trabajado como licenciados los sujetos de los cluster "Disponibilidad geográfica, pero no en puestos de trabajo que requieran esfuerzo fisico", y "Disponibilidad total", como oficiales de segunda los del conglomerado "Sin disponibilidad geográfica ni sobre horarios de trabajo poco frecuentes", y como oficiales de primera aquellos que afirman no tener Disponibilidad $\left(\chi^{2}=46,396 ;\right.$ g.l. $\left.=21 ; \mathrm{P}=0,001\right)$. 
TABLA 10: Patrones de Disponibilidad y motivos por los que está en desempleo.

\begin{tabular}{|c|c|c|c|c|c|c|}
\hline & & $\begin{array}{c}\text { Disponibilidad } \\
\text { geográfica, no } \\
\text { para esfuerzo } \\
\text { físico }\end{array}$ & $\begin{array}{c}\text { Sin disp. } \\
\text { Geográfica y } \\
\text { sin disp. de } \\
\text { horarios raros }\end{array}$ & $\begin{array}{c}\text { Disponibilidad } \\
\text { total }\end{array}$ & $\begin{array}{c}\text { Sin } \\
\text { disponibilidad }\end{array}$ & Total \\
\hline \multirow{4}{*}{$\begin{array}{c}\text { Por que } \\
\text { está en } \\
\text { desempleo }\end{array}$} & $\begin{array}{l}\text { No está en } \\
\text { desempleo }\end{array}$ & $\begin{array}{c}27 \\
24,3 \%\end{array}$ & $\begin{array}{c}37 \\
33,3 \%\end{array}$ & $\begin{array}{c}30 \\
27,0 \%\end{array}$ & $\begin{array}{c}17 \\
15,3 \%\end{array}$ & $\begin{array}{c}111 \\
100,0 \%\end{array}$ \\
\hline & $\begin{array}{l}\text { No } \\
\text { trabajaba }\end{array}$ & $\begin{array}{c}31 \\
37,3 \%\end{array}$ & $\begin{array}{c}25 \\
30,1 \%\end{array}$ & $\begin{array}{c}16 \\
19,3 \%\end{array}$ & $\begin{array}{c}11 \\
13,3 \%\end{array}$ & $\begin{array}{c}83 \\
100,0 \%\end{array}$ \\
\hline & \begin{tabular}{|l|} 
Despido o \\
finalización \\
de contrato
\end{tabular} & $\begin{array}{c}22 \\
18,8 \%\end{array}$ & $\begin{array}{c}50 \\
42,7 \%\end{array}$ & $\begin{array}{c}20 \\
17,1 \%\end{array}$ & $\begin{array}{c}25 \\
21,4 \%\end{array}$ & $\begin{array}{c}117 \\
100,0 \%\end{array}$ \\
\hline & Total & $\begin{array}{c}80 \\
25,7 \%\end{array}$ & $\begin{array}{c}112 \\
36,0 \%\end{array}$ & $\begin{array}{c}66 \\
21,2 \%\end{array}$ & $\begin{array}{c}53 \\
17,0 \%\end{array}$ & $\begin{array}{c}311 \\
100,0 \%\end{array}$ \\
\hline
\end{tabular}

$\chi^{2}=17,241 ;$ g.l. $=6 ; \quad P=0,008$

En cuanto a aquellos individuos que afirman estar en desempleo, pero realizan algún trabajo esporádico, parece que proporcionalmente se agrupan más en el cluster "Sin disponibilidad geográfica ni sobre horarios de trabajo poco frecuentes" $\left(\chi^{2}=7,310\right.$; g.l. = 3; $\mathrm{P}=0,063)$.

Aparecen diferencias estadísticamente significativas en el uso de Internet para la búsqueda de empleo, sólo los individuos del grupo "Disponibilidad geográfica, pero no en puestos de trabajo que requieran esfuerzo físico" afirman que lo utilizan o que lo harán $\left(\chi^{2}=8,407\right.$; g.l. $\left.=3 ; \mathrm{P}=0,038\right)$.

Por último, también se analizan las diferencias en función del sueldo mensual neto mínimo que aceptaría, se tomaron como referencia los cuartiles para formar cuatro grupos en función del salario, y parece que el límite más alto, los que más piden (más de 901,52 €) son los que tienen "Disponibilidad total" y los que menos los del cluster "Sin disponibilidad geográfica ni sobre horarios de trabajo poco frecuentes" (Tabla 11).

No existen diferencias estadísticamente significativas entre los cuatro grupos de individuos cuando se toman en cuenta el sexo, el número de personas con quien vive, su situación económica, su nivel de francés y de informática (procesadores y hojas de cálculo), la experiencia laboral que tienen, el tiempo trabajado en áreas relacionadas con sus estudios o puestos en los que quiere trabajar, el tipo de contratos que ha tenido, si realiza algún trabajo aunque sea de forma esporádica, los planteamientos ante la búsqueda de empleo, si busca trabajo en la actualidad y las posibilidades que cree tener de encontrar trabajo.

\section{Descripción de perfiles}

Disponibilidad geográfica, pero no en puestos de trabajo que requieran esfuerzo físico

Son individuos que podrían aceptar puestos de trabajo en provincias limítrofes o alejadas de su actual residencia, o incluso en el extranjero, pero que afirman no poder o no que- 


\section{TABLA 11: Patrones de Disponibilidad y sueldo mensual neto mínimo que aceptaría.}

\begin{tabular}{|c|c|c|c|c|c|c|}
\hline & & $\begin{array}{c}\text { Disponibilidad } \\
\text { geográfica, no } \\
\text { para esfuerzo } \\
\text { físico } \\
\end{array}$ & $\begin{array}{c}\text { Sin disp. } \\
\text { geográfica y } \\
\text { sin disp. de } \\
\text { horarios raros }\end{array}$ & $\begin{array}{c}\text { Disponibilidad } \\
\text { total }\end{array}$ & $\begin{array}{c}\text { Sin } \\
\text { disponibilidad }\end{array}$ & Total \\
\hline \multirow{5}{*}{$\begin{array}{c}\text { Sueldo } \\
\text { mensual } \\
\text { neto } \\
\text { mínimo } \\
\text { que } \\
\text { aceptaría }\end{array}$} & $\begin{array}{l}\text { Menos de } \\
601,01 €\end{array}$ & $\begin{array}{c}13 \\
28,9 \%\end{array}$ & $\begin{array}{c}18 \\
40,0 \%\end{array}$ & $\begin{array}{c}5 \\
11,1 \%\end{array}$ & $\begin{array}{c}9 \\
20,0 \%\end{array}$ & $\begin{array}{c}45 \\
100,0 \%\end{array}$ \\
\hline & $\begin{array}{l}\text { Entre } 601,01 \\
\text { y } 781,32 €\end{array}$ & $\begin{array}{c}19 \\
23,5 \% \\
\end{array}$ & $\begin{array}{c}35 \\
43,2 \%\end{array}$ & $\begin{array}{c}14 \\
17,3 \%\end{array}$ & $\begin{array}{c}13 \\
16,0 \%\end{array}$ & $\begin{array}{c}81 \\
100,0 \%\end{array}$ \\
\hline & $\begin{array}{l}\text { Entre } 781,32 \\
\text { y } 901,52 €\end{array}$ & $\begin{array}{c}7 \\
19,4 \%\end{array}$ & $\begin{array}{c}18 \\
50,0 \%\end{array}$ & $\begin{array}{c}4 \\
11,1 \%\end{array}$ & $\begin{array}{c}7 \\
19,4 \% \\
\end{array}$ & $\begin{array}{c}36 \\
100,0 \%\end{array}$ \\
\hline & $\begin{array}{l}\text { Más de } \\
901,52 € €\end{array}$ & $\begin{array}{c}25 \\
25,8 \%\end{array}$ & $\begin{array}{c}26 \\
26,8 \%\end{array}$ & $\begin{array}{c}30 \\
30,9 \%\end{array}$ & $\begin{array}{c}16 \\
16,5 \%\end{array}$ & $\begin{array}{c}97 \\
100,0 \%\end{array}$ \\
\hline & Total & $\begin{array}{c}64 \\
24,7 \%\end{array}$ & $\begin{array}{c}97 \\
37,5 \%\end{array}$ & $\begin{array}{c}53 \\
20,5 \%\end{array}$ & $\begin{array}{c}45 \\
17,4 \%\end{array}$ & $\begin{array}{c}259 \\
100,0 \%\end{array}$ \\
\hline
\end{tabular}

$\chi^{2}=15,508 ;$ g.l. $=9 ; P=0,078$

rer aceptarlos si se realizan en condiciones de temperaturas extremas, al aire libre o si requiere esfuerzo físico.

Tienen entre 22 y 24 años, solteros, sin personas a su cargo, no están en desempleo o llevan menos de un año en esa situación ya que no trabajaban anteriormente. Tienen estudios superiores, poseen un nivel de inglés medio o alto, realizan un curso de formación y han recibido alguno más anteriormente. Su categoría laboral ha sido o es la de licenciado, y cuando busquen trabajo lo harán a través de Internet.

Sin disponibilidad geográfica ni sobre horarios de trabajo poco frecuentes

Afirman que no podrían aceptar un trabajo en una provincia alejada de su actual residencia, en provincias limítrofes o en el extranjero, ni para aceptar horarios partidos, nocturnos, a turnos y/o horarios de tarde.

Tienen menos de 21 años, viven con su familia, no trabajan o están en desempleo pero realizan algún trabajo esporádico, no han realizado nunca un curso de formación, su contrato finalizó o fueron despedidos, han realizado estudios de formación profesional, poseen un nivel de inglés básico, su mayor categoría laboral ha sido la de oficial de segunda, y no buscarán trabajo a través de Internet.

\section{Disponibilidad Total}

Afirman tener disponibilidad total: en los desplazamientos, condiciones ambientales, jornadas cortas y condiciones atractivas. Además tampoco parecen carecer de disponibilidad geográfica. 
Tienen de 25 a 29 años, solteros, sin personas a su cargo, viven por su cuenta, están realizando un curso de formación, tienen un nivel máximo de estudios de BUP y sus conocimientos de inglés son medios o altos. Su mayor categoría laboral ha sido como encargado.

\section{Sin Disponibilidad}

En este grupo se reúnen 53 individuos que dicen no tener Disponibilidad para nada, ni siquiera para aceptar condiciones atractivas.

Tienen más de 30 años, casados, con personas a su cargo, viven por su cuenta, no están estudiando, llevan en desempleo más de un año y no realizan trabajos esporádicos, fueron despedidos o finalizó su contrato, sus estudios son de FPI y no han realizado nunca un curso de formación, ni tienen conocimientos de inglés o éstos son básicos. Su mayor categoría laboral ha sido oficial de segunda y no utilizarán Internet para buscar trabajo.

\section{Conclusiones}

Lo que menos aceptarían en un puesto los individuos que componen la muestra es un puesto de trabajo situado en una provincia alejada, con altas o bajas temperaturas, con distintos turnos, con riesgos para la seguridad o salud, con horario de noche, al que tardara en llegar más de una hora, o que esté en el extranjero.

Las condiciones más deseables son tardar entre 15 y 30 minutos en llegar al trabajo, un horario de mañana, y que requiera utilizar la vista o el oído.

Los seis factores obtenidos (disponibilidad Geográfica, en los desplazamientos, para realizar esfuerzos físicos, sobre horarios de trabajo raros, sobre jornadas cortas, y sobre condiciones de trabajo atractivas) reflejan lo que los individuos quieren y pueden aceptar, o no, de un puesto de trabajo. Los índices "Disponibilidad sobre jornadas cortas" y "Condiciones atractivas" discriminan poco entre los cuatro conglomerados de individuos, quizás habría que plantearse continuar teniéndolos en cuenta.

Con las puntuaciones obtenidas por los sujetos en esos factores se obtuvieron cuatro conglomerados o perfiles de sujetos.

El primer grupo de individuos manifiesta tener disponibilidad geográfica, son individuos jóvenes con estudios superiores. Desde el punto de vista de la intervención, quizás convendría informarles sobre las posibilidades del mercado de trabajo tanto dentro como fuera de España.

El segundo grupo dice no tener disponibilidad geográfica ni tampoco sobre horarios de trabajo poco frecuentes. Son sujetos muy jóvenes, que viven con sus padres y que obtienen algunos ingresos con trabajos esporádicos. Parecen poner muchas restricciones condiciones al trabajo que les gustaría tener, quizás sea porque no tienen prisa. Quizás habría que centrar los esfuerzos en ayudarles a preparar la búsqueda de empleo y a generar estrategias de búsqueda activa (Blau, 1993, 1994; citado en Saks y Ashforh, 1999), ya que ambos están muy relacionados con lo que los individuos están dispuestos a aceptar y lo que no.

Disponibilidad total dicen tener las personas del tercer cluster, parece que tienen claro que quieren trabajar. Si su perfil y cualificación está en línea con las necesidades del merca- 
do de trabajo no tienen porque tener problemas para conseguirlo, pero hay que comprobarlo y poner en marcha las acciones oportunas.

El último grupos afirma no tener disponibilidad para nada. Son los mayores, y llevan en desempleo más de un año. La pregunta clave sería: ¿Quieren trabajar?

Por lo general, trabajar es algo bien visto en la sociedad, y no hacerlo supone que muchos etiqueten a esa persona como en situación de exclusión. Contestar a la pregunta de ¿quiero trabajar? no siempre es fácil. Requiere un ejercicio de sinceridad, de asunción de un determinado rol, de dar explicaciones a los demás. Sin embargo, hay personas que no tienen porqué hacerlo, porque no tienen necesidades económicas a corto, medio y/o largo plazo. El orientador laboral debe detectar si el usuario está dentro de ese colectivo, con delicadeza, y ayudarle a aclarar y reconocer sus deseos.

Si quiere trabajar, hay que hacerle analizar su perfil y mostrarle las posibilidades del mercado de trabajo, no sólo las ofertas, sino también las características de éstas, y de los puestos ocupados. Ese será el primer paso para realizar planteamientos realistas y construir itinerarios basados en la premisa de que se desean recorrer. El estudio de las conductas exploratorias, con larga tradición en Orientación Profesional (Rodríguez, Sandín, Buisan, 2000) contribuye a profundizar en las actitudes de búsqueda.

Cuando a los individuos se les pregunta "si pueden", en muchas ocasiones oyen "si quieren", quizás porque el poder es relativo y varía en función de una serie de aspectos. Centrarse en lo que quieren puede que les permita acentuar su autoconcepto, variable clave en el desarrollo de carrera del individuo (p.e. Ferreira, 1999).

A la hora de interpretar los datos empíricos obtenidos hay que tener en cuenta que a pesar de que en el protocolo aplicado se pregunta a los sujetos por el grado en que aceptarían un puesto de trabajo, en la mayoría de los casos están respondiendo en función de lo que desean o no desean, y no en la medida en que puede o no puede.

Quizás sería bueno unir en una sola escala datos relativos a lo que los sujetos están dispuestos a hacer y lo que aceptarían o no aceptarían, pues si identifican no querer con no poder se están moviendo en el área actitudinal, y las intervenciones podrían ir unidas. Sería después el orientador el que tuviera que delimitar si la negativa se debe a una u otra causa y establecer los apoyos, pero con carácter individual, y prestando una especial atención a las recomendaciones de la Asociación Internacional de Orientación Educativa y Profesional en torno al mantenimiento la autoestima de los desempleados.

Otro aspecto a tener en cuenta en futuras investigaciones es relacionar lo que están dispuestos a aceptar con otras variables como sus metas, lo que están dispuestos a hacer, o el grado de indecisión o decisión de las personas (éstos últimos tal y como los entienden Callanan y Greenhaus, 1992). Además, hay que prestar atención a los distintos perfiles de individuos, e incluso profundizar en los patrones dentro de colectivos específicos como el de desempleados de larga duración, ya que también presentan necesidades diferenciales, y por lo tanto requieren de intervenciones planificadas a su medida (Campbell, 1998).

La escala permite detectar en que medida está disponible cada persona. La disponibilidad resulta un elemento clave a la hora de explicar que muchos puestos de trabajo no se cubren, a pesar de existir candidatos con los conocimientos, habilidades, y actitudes necesarias. Pero, en muchas ocasiones, se renuncia a un trabajo porque se quiere el mejor trabajo, y ese no aparece, o simplemente no existe. Transmitir la realidad del mercado de tra- 
bajo a cada persona que participa en un proceso de orientación laboral es un deber del orientador, como lo debería ser reducir expectativas sobredimensionadas e irreales Sin embargo, la decisión final, afortunadamente, siempre la tiene el orientado, porque tiene derecho a equivocarse.

Como se aprobó en la declaración de la Asociación Internacional de Orientación Educativa y Profesional (AIOEP) sobre Orientación Educativa y Profesional en el año 2001 en París (citado en la Revista Española de Orientación Profesional, 2001, p. 379): la orientación eficaz puede ayudar a las personas a descubrir sus habilidades y capacidades, y ello le puede permitir una educación, una formación profesional y un empleo adecuados. Pero también señala que deben llevarse a cabo con la participación voluntaria y activa de los clientes.

\section{Referencias bibliográficas}

Aramburu-Zabala (1998). "Determinantes psicosociales de la búsqueda de empleo". Revista de Psicología del Trabajo y las Organizaciones, 14, 3, pp. 315-331.

Asociación Internacional de Orientación Educativa y Profesional (2001). Declaración de la AIOEP sobre Orientación Educativa y Profesional. París.

Barba-Romero, S. (1984). Técnicas de Apoyo a la toma de decisiones en la Administración pública. Instituto Nacional de la Administración Pública. Madrid.

Barba-Romero, S. (1987). "Panorámica actual de la decisión multicriterio discreta". Investigaciones Económicas, XI, 2, pp. 279-308.

Barba-Romero, S. (1990). "A comparative review of discrete MCDM software. Ponencia presentada en OR'90”. International Conference on Operations Research. Viena.

Barrios, L. y Rubio, M. (1992). Manual de usuario de la aplicación SSD_CIABSI. Sistema de Soporte a la decisión. Ministerio para las Administraciones Públicas. Madrid.

Bravo, M. J., Peiró, J. M. y Rodríguez, I. (1996). "Satisfacción Laboral”. En J. M. Peiró y F. Prieto (Eds.) Tratado de Psicología del Trabajo. Volumen I: La actividad laboral en su contexto (pp. 342-394). Valencia: Síntesis Psicología.

Brans, J. P. y Vincke, Ph. (1985). "A preference ranking organization method, the PROMETHEE method". Management Sciencie, 31, 6, pp. 647-656.

Callanan, G. A. \& Greenhaus, J. H. (1992). "The career indecision of managers and professionals: an examination of multiple subtypes". Journal of Vocational Behavior, 41, pp. 212-231.

Campbell, M. (1998). Local management for more effective employment policies. París: Organisation for Economic Co-operation and Development (OECD).

Fernández, J. y Aramburu-Zabala, L. (2000). "Inserción y preparación para el empleo: un estudio longitudinal". Revista de educación, 321, pp. 137-152.

Ferreira, J. (1999). "Connaissance de soi: quelques questions philosophiques et psychologiques; implications pour l'orientation". Revista Española de Orientación Profesional, 10, 17, pp. 13-21.

Instituto Nacional de Empleo (www.inem.es). 
Instituto Madrileño para la Formación (IMAF) (www.comadrid.es),

International Association for Educational and Vocational Guidance (IAEVG). Strategies for Vocational Guidance in the Twenty-first Century. www.unevoc.de/congress/pdf/ref-iaee.pdf. Enero de 2003

M.O.W. International Research Team (1987). The Meaning of working: An International View. London: Academic Press.

Pescador, F. M. (1989). Sistema ALTOR. Sistema Informático de Somosaguas (UCM). Madrid.

Piqueras, R. y Rodríguez, A. (1998). "Evaluación del cambio de actitudes en búsqueda de empleo". IV Congreso Nacional de Psicología del Trabajo y de las Organizaciones. Valladolid. En htto://usuarios.lycos.es/orh/rafaelpg/ecabe.htm, bajado el 20 de enero de 2003.

Real Academia de la Lengua (1992). Diccionario de la lengua española. (21 ed.) Madrid: Real Academia de la Lengua.

Rodríguez, M. L., Sandín, M. P., y Buisán, C. (2000). "La conducta exploratoria: concepto y aplicaciones en orientación profesional”. Revista de Educación, 321, pp. 153-186.

Saks, A. M. \& Ashforth, B. E. (1999). "Effects of individual differencies and job search behaviors on the employment status of recent university graduates". Journal of Vocational Behavior, 54, pp. 335-349.

Tabachnick, B. G. y Fidell, L. S. (1983). Using Multivariate Statistics. New York, Harper and Row.

Fecha de recepción: 20-02-2003

Fecha de revisión: 18-11-2003

Fecha de aceptación: 05-11-2004 